\title{
Happiness as a harmonising path for bringing higher education towards sustainability
}

\section{Carolina Escobar-Tello \& Tracy Bhamra}

\section{Environment, Development and} Sustainability

A Multidisciplinary Approach to the Theory and Practice of Sustainable Development

ISSN 1387-585X

Volume 15

Number 1

Environ Dev Sustain (2013) 15:177-197

DOI 10.1007/s10668-012-9382-4

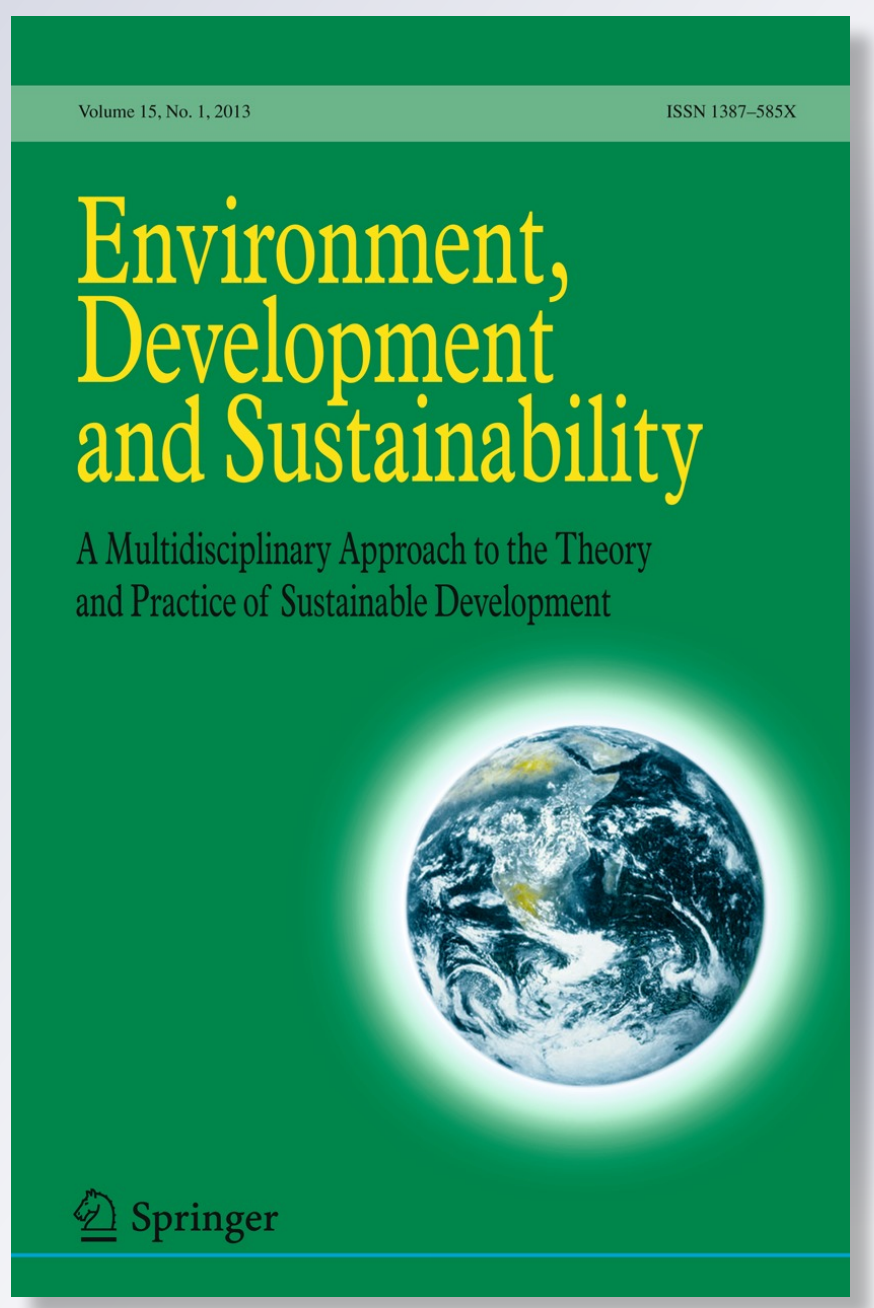

Springer 
Your article is protected by copyright and all rights are held exclusively by Springer Science+Business Media B.V.. This e-offprint is for personal use only and shall not be selfarchived in electronic repositories. If you wish to self-archive your work, please use the accepted author's version for posting to your own website or your institution's repository. You may further deposit the accepted author's version on a funder's repository at a funder's request, provided it is not made publicly available until 12 months after publication. 


\title{
Happiness as a harmonising path for bringing higher education towards sustainability
}

\author{
M. Carolina Escobar-Tello • Tracy Bhamra
}

Received: 13 February 2012/Accepted: 6 August 2012/Published online: 22 August 2012

(C) Springer Science+Business Media B.V. 2012

\begin{abstract}
This paper is a reflection of an innovative project that complements existing higher education for sustainable development (HESD) approaches within universities by providing an alternative path to embed sustainable lifestyles within the student population. It presents the SLEUTH project; an initiative born out of the need to reduce energy consumption of students at university but that, due to its systemic design, transforms and goes beyond purely energy reduction and brings Happiness as an approach to build sustainable lifestyles. This is the distinct feature of this initiative, proposing it as adding value to existing HESD approaches. The paper describes and discusses the collaborative building process, implementation and results in detail. The experiences gathered during the project are used and analysed through 'participant observation', 'documents', 'questionnaires' and 'theme-ing coding' techniques as a means to understand the richness and diversity of the data resulting from a combination of formal and informal learning settings. Through empirical evidence, this analysis presents 'real life' evidence to suggest, firstly the initiative's design success, its impact on energy consumption and contribution to happiness and sustainable lifestyles. Secondly, a successful example for the contribution to existing HESD frameworks that move away from indoctrination and instead leans towards proactiveness, self-organisation and voluntary collective action.
\end{abstract}

Keywords Sustainability · Education - Sustainable lifestyles · Happiness · Universities · Pro-active citizenship

$\begin{array}{ll}\text { Abbreviations } \\ \text { HESD } & \text { Higher education for sustainable development } \\ \text { ESD } & \text { Education for sustainable development } \\ \text { SLEUTH } & \text { Sustainable lifestyles-educating universities towards happiness } \\ \text { DESD } & \text { Decade of education for sustainable development }\end{array}$

M. C. Escobar-Tello $(\square) \cdot$ T. Bhamra

Loughborough Design School, Loughborough University, Leicestershire LE11 3TU, UK

e-mail: M.C.Escobar-Tello@lboro.ac.uk

T. Bhamra

e-mail: T.Bhamra@lboro.ac.uk 


\section{Introduction}

Everything around us, from simple artefacts to products, buildings and complex services or systems, is significant in the way we behave and interact with our surroundings. They play a role in the way we shape our lifestyles and the consequences to the environment (Shove et al. 2007; Jackson 2008). Sustainable development has been identified as being of paramount importance in order for humans to survive on this planet (Michaelson et al. 2009; Abdallah et al. 2009). This implies that we all have to change the way we live, from the way we behave ourselves to how we relate to our surroundings. Ultimately, this means changing our lifestyles into sustainable ones.

Universities, being the place where some of the younger generation and important future decision-makers are educated with the necessary competences to navigate the future, are not an exception. It is now recognised that education for sustainable development (ESD) contributes to change the attitudes and behaviour of people to carry out their collective responsibilities and duties (Martins et al. 2006; Fadeva and Mochizuki 2010). The focus of this paper is precisely on the type of education needed to do this successfully. SLEUTH (sustainable lifestyles-educating universities towards happiness) project is used as an example that considers and adds to this process of universities transition towards ESD, specifically HESD (higher education for sustainable development), through a novel approach. It is the design outcome of an initiative, whose concept anchors on embedding happiness triggers and sustainable design characteristics within products, services or systems as a strategy to contribute to people's overall happiness, hence promoting sustainability awareness and a transition towards sustainable communities and lifestyles (Escobar-Tello 2011). 'Happiness' - being an intrinsic value and an immediate element that does relate in close proximity to the individual-engages people and can be used as leverage to bring them closer to the sustainability concept, which in contrast is often perceived as being too abstract and to which they cannot relate (Sustainable Consumption Roundtable 2006).

\subsection{Higher education for sustainable development}

The UNESCO led decade of education for sustainable development (DESD) 2005-2014 (UNESCO 2009) is the designated lead agency to promote the implementation of ESD. So far, their mid-point of the decade review shows that multiple actions and significant changes have occurred in the reorientation of teaching and learning towards sustainable development around the world. This has brought initiatives that advance the underlying principals, values and purpose of education curricula but also widen and embrace a whole range of other sustainable development components such as peace education, human rights education, consumer education, health education, biodiversity education, gender education and citizenship. Furthermore, governments' interests in ESD have increased and, most notably, have committed themselves to include the framework in their existing education programmes and systems, particularly in higher education.

Unfortunately, despite the aforementioned positives, evidence suggests that in practice, there is still a long way to go; the world is not getting any better and a high resistance to change seems to be the worldwide norm (Ferrer-Balas et al. 2010). The educational system has not yet had a real transformation at all levels (Sterling and Scott 2008).

It is difficult for institutions in HE to change; their foundations are still embedded by individual and fragmented learning (i.e. organised by disciplines, schools) where 
interdisciplinary collaboration is often overlooked, technology is seen as the main solution to human problems, and individual success is independent and non-accountable for impacts on the greater good (environmental, social or economic) (Cortese 2003). In the meantime, society has changed; the variables and complexity of our current societal system are different from those that shaped the twentieth century, and our understanding of them is even messier (Meadows 2002). Future generation's 'navigation' and survival no longer relies on technology and economic growth, but on social capital in hand with natural capital (Hawken et al. 1999; Daily 1997; Meadows et al. 2004). This still needs to be reflected strongly in education, a deep paradigm shift is required.

To this end, the education community is now questioning the extent of the achievements in current HESD frameworks and is divided on how best to respond to 'education for sustainability' (Wals and Jickling 2002; Nath 2003; Vare and Scott 2007, Cortese 2003). They question the overarching goals and process of it with regard to sustainability, recognise the limitations in the 'ill-defined' nature of the term sustainability, and propose a more emancipatory perspective where a systemic perspective emphasises collaboration and cooperation. Here, the 'space' for the students to discuss different views and ways of understanding the world is created as part of an integrated, self-organised, active and participatory context of learning embodied by the learners themselves instead of a prescriptive one which results from an indoctrinating, hierarchical and authoritative perspective. The SLEUTH project's underlying values explore HESD from this perspective.

\subsection{Happiness as part of an HESD approach}

Our present economic structure does not help people to focus on those things that offer meaning and purpose to our lives, and instead it reinforces and pushes us away from them. We live in a world driven by economic growth. Its present 'material centred culture' has been sold to us as a paradigm whose 'promise' is that products deliver a better, infinite growing, easy-living lifestyle where people can have more time (freedom) to do pleasurable things and make their own choices (Manzini 2006). This fallacy has an important impact on our individual and collective happiness level; among other examples, it has led us to place too much value on 'externalities' (i.e. products), consume and discard at high rates (waste), demand total individuality (personalization) and erode any form of community or collectivity (Toffler 1970; Cooper 2000; Jackson 2008). It has led us to 'confuse' the satisfaction provided by material acquisition with the idea that it equals happiness.

Here lies the first hurdle, although 'happiness' is pivotal to our existence (Veenhoven 2004; Csikszentmihalyi 2002), understanding it, grasping its real concept, is a difficult task. For the purpose of this research, then, based on an extensive review in positive psychology, sociology and neurochemical literature (Narada 1991; Diener et al. 2003; Brülde 2007; Layard 2005; Lemonick 2005; Sheldon and Lyubomirsky 2004; Veenhoven 2001), the following definition was established:

Happiness is a state of deep contentment (serenity and fulfilment) with one's life, which results from the combination of three variables: feeling in a positive mood (1), life satisfaction (2) and genetics (3). (Escobar-Tello 2011; Table 1).

Identifying what brings happiness is the second hurdle. Key characteristics may have been identified but they do not guarantee that everybody will feel the same level of happiness when under their influence. The most general seem to be to find activities individuals can get engaged with, activities that correspond to personal interests and values 
Table 1 Happiness definition in detail

\begin{tabular}{lll}
\hline Feeling happy & Life satisfaction & Genetics \\
\hline $\begin{array}{ll}\text { Affective variable-feeling good; } \\
\text { having good and bad moods, } \\
\text { emotions, but feeling happy in } \\
\text { the overall judgement }\end{array}$ & $\begin{array}{l}\text { Cognitive variable-feeling } \\
\text { satisfied with one's life; being } \\
\text { able to look back and also to the } \\
\text { future and judge that life has } \\
\text { been/is/will be good. Being } \\
\text { optimistic. This also includes } \\
\text { being and doing well, not just } \\
\text { feeling well }\end{array}$ & $\begin{array}{l}\text { Neurochemistry variable- } \\
\text { physical characteristics of a } \\
\text { happy brain have come to see } \\
\text { that those traits have a powerful } \\
\text { influence on the rest of the body }\end{array}$ \\
& &
\end{tabular}

(Wallis 2005; Sheldon and Lyubomirsky 2004; Diener and Scollon 2003; Layard 2005; Jackson and McBride 2005). For example, being creative about them (varying the way they are done) will assure pleasure as this will give them a character of flexibility and constant renewal. It is also important to interact with others and share, with family and friends perhaps, these new activities or set goals. Also try to avoid total individualism and alienation. Finally, it is recommended to reflect on one's life, be kind to others and be grateful for all that one may have. This strengthens self-esteem and social networks.

So all in all, strong social networks motivate individuals to make progress and reach their set goals. Focusing on the experiences provided, rather than on the vehicles that aid to deliver them (i.e. products), seems to be the key. While increased material consumption might be good for the economy, it certainly does not contribute to peoples' lifestyles, happiness (Papanek 1985; Whiteley 1993) or to the environment (Weizacker et al. 1998; Hinte 1997). In fact, our current consumption behaviour is indeed an excellent example to illustrate the unsustainable society we live in. On the contrary, evidence seems to suggest that sustainable societies invite people to lead sustainable lifestyles and be happier, and vice versa (two-way relationship). This is a complex phenomenon that goes beyond the focus of this paper; however, the earlier part of the research allowed the identification of specific characteristics that contribute to both of them (Escobar-Tello and Bhamra 2009). Figure 1 illustrates these characteristics.

In this way, the SLEUTH project was proposed as an opportunity to further explore this phenomenon and add empirical evidence through 'real life' trials that would contribute to corroborate the 'overlap' condition illustrated in Fig. 1. In addition, the project's setting was used and recognised as a potential to add to existing HESD frameworks by providing a novel approach where effectively the 'ill-defined' nature of the term sustainability is unpicked. The purpose of the next sections is then to review and discuss the potential of such initiative in detail.

\section{Description of the conceptual design behind the SLEUTH project}

From a distance, the SLEUTH project could be simplified as an initiative that aims to address energy reduction targets set for the United Kingdom through the reduction in energy consumption at a university, specifically within halls of residence. In reality, it is a complex system in which the design concept goes beyond just saving energy by building on Happiness and core building blocks of sustainable lifestyle issues such as communities, pro-active citizenship, skills development, sharing and low material consumption. In 


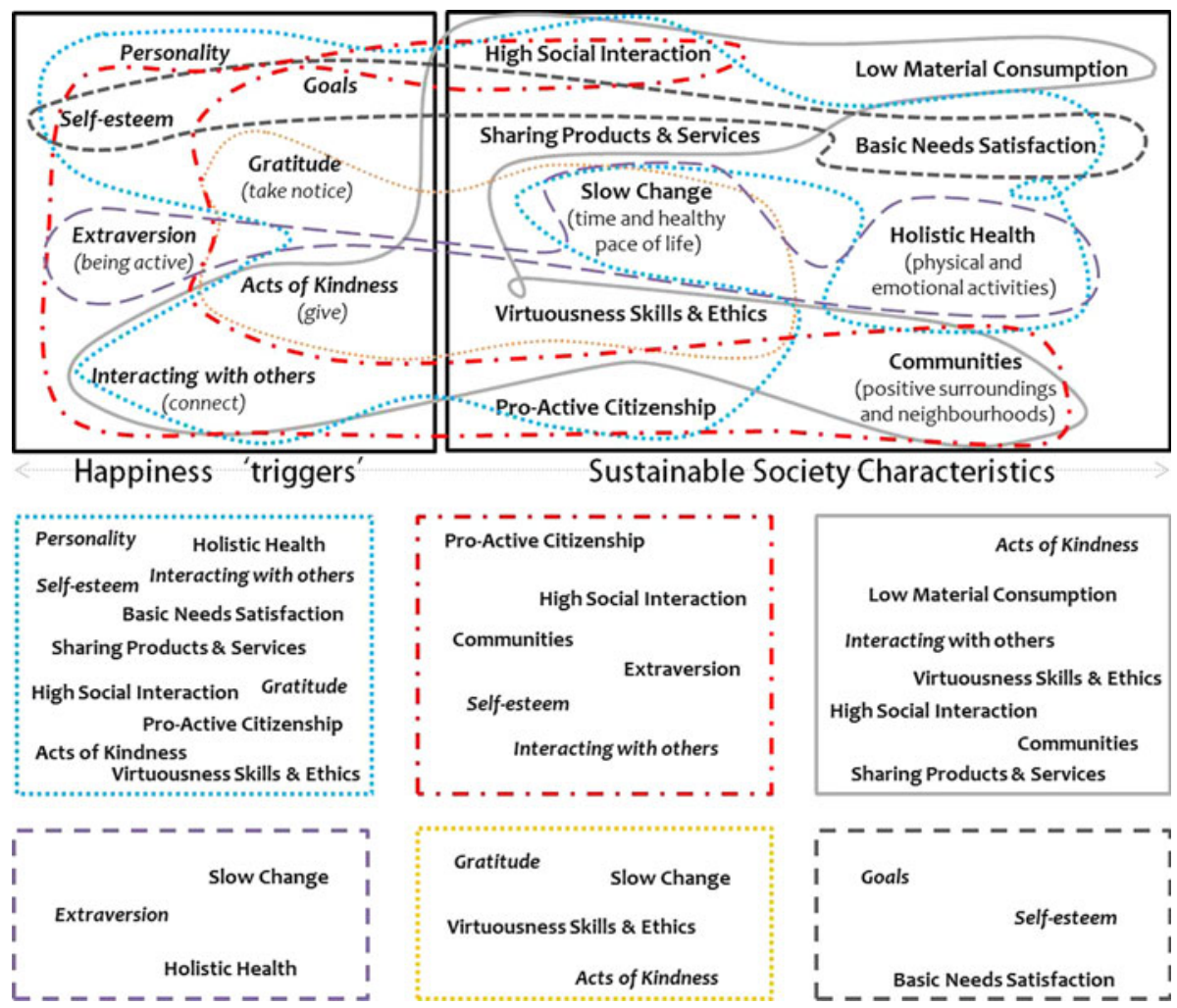

Fig. 1 Happiness and sustainable lifestyles characteristics-examples of 'overlap phenomena'

practical terms, it approaches the problem through a holistic perspective that engages the students in a competition rather than implementing a product or specific technology that reduces energy consumption in an automatic way. It instead embraces two main areas within the design: a reward system and a history/storytelling narrative, both aiming to enable reflection. Ultimately, it aimed to:

Contribute to finding a path for universities to embed sustainable lifestyles at their core while allowing its participants to shape its course.

In broad terms, the project included 3 main components:

(A) an individual 'control/reward' card for each student that accrues points for 'sustainable behaviours'.

(B) A 'social network' platform to follow (monitor) the halls competition as well as the participants' interaction and individual behaviours.

(C) A knowledge transfer system (within the social network platform), where the project results data are saved (i.e. energy use/savings data, waste and recycling data and happiness data). The database saves also the 'social interactions' of the competition; therefore, the vast knowledge of the activities and skills available at the university are saved too. This represents a bank of the 'university and community's resilience' potential (History). 
Table 2 Collaboration team-criteria and potential stakeholders

\begin{tabular}{|c|c|}
\hline Criteria & Potential stakeholders \\
\hline $\begin{array}{l}\text { Environment/sustainability/ } \\
\text { sustainable development }\end{array}$ & $\begin{array}{l}\text { Sustainability management, facilities management, students' union } \\
\text { ethical and environmental officer }\end{array}$ \\
\hline Energy management services & Energy technicians-facilities management. \\
\hline $\begin{array}{l}\text { Students' extracurricular interests } \\
\text { and activities }\end{array}$ & $\begin{array}{l}\text { Careers centre-employability award, student union (president, RAG } \\
\text { officer, community action, societies activities, athletic union) }\end{array}$ \\
\hline $\begin{array}{l}\text { Students' accommodation } \\
\text { services/halls }\end{array}$ & $\begin{array}{l}\text { IMAGO services, chosen halls of residence warden, sub-wardens and } \\
\text { committee }\end{array}$ \\
\hline Social networking services & Sustainable design research group (SDRG) \\
\hline
\end{tabular}

\subsection{Selection of scenario and participants sample}

Being that the researcher was based at Loughborough University, ${ }^{1}$ the university and its students living in Halls of Residence on campus was selected as the scenario and participants sample to take part in the trials. Taking into account the conceptual design requirements, it was necessary to choose a self-catered hall with a mixed group of residents. For this reason, one specific Halls of Residence was chosen for the trial. This has a total of 354 bedrooms divided into 6 blocks that accommodate four types of students: UK undergraduates, Sports elite athletes, overseas students on exchange programmes and Art Foundation students.

\section{Building process}

The starting point of this process consisted of identifying the key stakeholders within the different areas of the university. The criteria applied to do this are summarised in Table 2. Subsequently, the identified areas were approached with the aim of setting up a voluntary Collaboration Team that would support the project.

\subsection{Project development}

In total, the project lasted 8 months. In view of the time frame and resources available to this research project, it was not possible to implement the conceptual design in its totality. It was therefore necessary to adjust it and select from the original idea the most representative requirements as follows:

- Development and setting up of the SLEUTH social network platform

An open source platform was used to build and upload the virtual platform of the competition.

- Development of the activities portfolio

This portfolio included 3 types of activities: 'Special Events', 'Daily Activities' and 'I Say, I Do, I make' activities. Table 3 explains these in detail. It must be noted that the

1 Among the top 20 universities in the United Kingdom, with international reputation for excellence in teaching and research, strong links with industry, and unrivalled sporting achievement. 
Table 3 Best behaviours portfolio-types of activities

\begin{tabular}{|c|c|c|c|}
\hline & & Description & Selected examples \\
\hline \multirow[t]{3}{*}{$\begin{array}{l}\text { Best } \\
\text { behaviours } \\
\text { portfolio }\end{array}$} & $\begin{array}{l}\text { 'Special } \\
\text { events' }\end{array}$ & $\begin{array}{l}\text { One-to-one events proposed by } \\
\text { SLEUTH team. } \\
\text { Delivered by an expert in the chosen } \\
\text { particular area. } \\
\text { Participants to attend to the specific } \\
\text { events at a certain time and date. }\end{array}$ & $\begin{array}{l}\text { Energy use reduction workshop } \\
\text { Waste and Recycling Workshop. } \\
\text { Conservation day. } \\
\text { Introduction to sustainability } \\
\text { workshop. } \\
\text { Organic food event. } \\
\text { 'Quiz Nights and pizza!' } \\
\text { International buffet night }\end{array}$ \\
\hline & $\begin{array}{l}\text { 'Daily } \\
\text { activities' }\end{array}$ & $\begin{array}{l}\text { Activities proposed by SLEUTH } \\
\text { team. } \\
\text { Either virtual or live activities } \\
\text { Participants to do them at a specific } \\
\text { date and time (i.e. } 1 \text { day at } 5 \mathrm{pm} \text {, } \\
1 \text { week every day) }\end{array}$ & $\begin{array}{l}\text { Energy Challenge - follow up: How to } \\
\text { raise Energy savings? } \\
\text { How big is my footprint?-create } \\
\text { your habit and measure your } \\
\text { personal impact on the planet! } \\
\text { Gratitude journal keeping }\end{array}$ \\
\hline & $\begin{array}{l}\text { 'I Say, I } \\
\text { Do, I } \\
\text { make' }\end{array}$ & $\begin{array}{l}\text { Activities proposed by the } \\
\text { participants. } \\
\text { Either virtual or live activities } \\
\text { Participants to do them in their own } \\
\text { time/particular period time } \\
\text { specified }\end{array}$ & $\begin{array}{l}\text { Cooking together Night! } \\
\text { Challenge: 'Communiversity'. } \\
\text { Challenge: Are you a volunteer?! } \\
\text { Badminton Game } \\
\text { You tell me! "Things that you should } \\
\text { know but no one ever told you ..." }\end{array}$ \\
\hline
\end{tabular}

selection of all the activities and events was based on their strong relation to sustainability issues and happiness triggers in one way or another. Energy saving was at the core of them.

- Development of the rewards portfolio

The aim of this portfolio was to reward the participating students for their efforts. The selection of rewards contained a wide array of options including entertainment, sport, outdoor and home alternatives. They were chosen based on values such as usefulness, novelty, and most importantly, based on their sustainability credentials (i.e. environmental awareness, ${ }^{2}$ eco-efficiency, ${ }^{3}$ fair-trade, ${ }^{4}$ eco-design, ${ }^{5}$ ethical living ${ }^{6}$ ). Examples included eco-designed MP3 players, sport powerballs, fair-trade product hampers, cinema vouchers and outdoor 'extreme' experiences.

\section{Implementation process}

For the purpose of the trials, the competition was open only to students that lived at the chosen Halls of Residence and participation was voluntary. There were two categories of participation: as an Individual and as a Team (a group of minimum 3 and maximum 6 students who had to share a kitchen and live on the same floor). The participants would earn points depending on the type of event and effort they got involved in. They would be rewarded fortnightly through a stepped rewards system and the amount of prizes handed

\footnotetext{
2 Products, services or systems which raise etc environmental awareness.

${ }^{3}$ Products, services or systems that use fewer resources, create less waste and pollution.

${ }^{4}$ Products, services or systems that improve and promote better trading conditions and sustainability.

5 Products, services or systems that consider the environmental impacts during their whole life cycle.

6 Products that limit their environmental and social impacts.
} 
out was reduced as the competition developed. On the other hand, the prize 'value' was increased. At the end of the trials, the students who had accrued the highest amount of points would win the final prize.

The trials ran for 8 weeks, time after which a 'Closure Event' was held with the aim of presenting the project's preliminary results, to recognise everyone's achievements and handout the prizes to the final winning students.

\subsection{SLEUTH experience}

Once the competition was launched, the participating students were able to logon to the Internet application (SLEUTH website) and create their personal username and profile (as individuals and/or as a team). Participants had full access to browse the website that would offer them the opportunity to join different 'activity groups', book themselves into the different activities proposed in the 'Best Behaviours' Portfolio, be pro-active about the initiative too (for example, propose their own activities, choose their favourite rewards, discuss topics and write about their own experiences) and check the results of the competition (i.e. how many points they have individually and/or as a team) as well .

Motivation was sustained through the social network platform and by the "project champions' (Halls of Residence warden and sub-wardens). Special emphasis was placed on encouraging pro-activeness and improving resilience; participants were constantly reminded that SLEUTH belonged to them, and therefore, they had complete freedom to shape it. Gaining points was also used as a 'motivation' feature. Finally, the rewards were used as a 'motivation' feature too. Participants were rewarded fortnightly but the ultimate goal was to win the overall competition (recognised both as individuals and teams). It was the recognition of meeting the aims of the project in the 'best' way:

- Address the energy reduction targets set for the United Kingdom;

- Build and enhance a sense of community within the students at Loughborough University;

- Raise sustainability awareness;

- Exceptional pro-active citizenship;

- Contribute to more sustainable lifestyles;

- Contribute to the community's Happiness and well-being.

\section{Methodology-data collection and analysis techniques}

The project was the object of the trial as well as a data collection technique as such; it provided a 'real life' environment to explore, observe and gather the genuine deep reactions of the sample group; especially in regard to sustainable lifestyles, energy reduction and happiness triggers. Table 4 presents a review of the methodology applied.

- The 'participant observation' approach and the 'participant-as-observer' role were used as a data collection technique during the one-to-one events. This role is effectively a mixture between being a participant and an observer at the same time (Robson 2002). The Theme-ing coding technique enabled the analysis of these data. This involved noting patterns, interpreting, generating meaning and in this way identifying and linking themes that run right through the data (Robson 2002; Miles and Huberman 1994; Morse and Richards 2002). 
Table 4 Review of methodology

\begin{tabular}{llll}
\hline & SLEUTH-one-to-one events & $\begin{array}{l}\text { SLEUTH- } \\
\text { social network } \\
\text { platform }\end{array}$ & $\begin{array}{l}\text { Happiness and sustainable lifestyles } \\
\text { contribution }\end{array}$ \\
\hline $\begin{array}{c}\text { Data } \\
\text { collection } \\
\text { techniques } \\
\begin{array}{c}\text { Analysis } \\
\text { techniques }\end{array}\end{array}$ & $\begin{array}{c}\text { Participant observation } \\
\text { approach and the } \\
\text { participant-as-observer role } \\
\text { Theme-ing coding technique }\end{array}$ & $\begin{array}{c}\text { 'Documents' } \\
\text { technique } \\
\text { Theme-ing } \\
\text { coding } \\
\text { technique }\end{array}$ & $\begin{array}{c}\text { 'Questionnaires' technique } \\
\text { 'Counting technique' and 'making } \\
\text { the analysis of the closed questions. } \\
\text { 'Template approach' was used for the } \\
\text { open-ended questions }\end{array}$ \\
\hline
\end{tabular}

- As for the social network platform, the 'document' data collection technique was found to be more appropriate and hence was used as a technique to provide detailed insights into participant's lives, attitudes and behaviour (Morse and Richards 2002). The 'document' data consisted essentially of the users' interactions with the platform and with other users, during the project. These data presented close and personal accounts of their experience, learning and the project outcomes through a varied array of sources (i.e. discussions, blogs, photos and diaries). Here again, the Theme-ing coding technique enabled the analysis of these data by identifying and linking themes that run right through the data. These were effectively key words and text threads-that led to important topics, variables or factors that were relevant to the project aims and confirmed the underlying research theory (i.e. the sustainable society characteristics illustrated in Fig. 1).

- 'Self-administered questionnaires' were identified as the most appropriate quantitative data collection technique to evaluate the project's potential to contribute to happiness and sustainable lifestyles. They permit to capture data on 'sensitive themes' and allows honesty, privacy and anonymity (Robson 2002). To this end, the questions were tailored to capture honest allusions of the success of the project as such, but mainly to capture allusions to sustainability (users' awareness, attitudes and behaviour) and to happiness. They aimed to understand whether the participants would keep using their experiences beyond the trials. Also to understand whether the identified benefits, changes, new attitudes and behaviours, towards 'happiness' and towards 'sustainability' would be embraced as part of their lifestyles in a permanent way or not.

With the aforementioned aims in mind, the questionnaire was divided into two stages. Stage one focused on measuring 'happiness'; it consisted of two closed questions adapted from The World Database of Happiness's item bank (Veenhoven 2001); care was taken in choosing a well-established method. Stage two focused on evaluating the users' feelings or attitudes towards 'sustainable lifestyles' and towards the SLEUTH project-success as such. This consisted of five short questions.

As outlined in Table 4, the identification of patterns through the theme-ing coding technique (Miles and Huberman 1994; Morse and Richards 2002) enabled the analysis of the questionnaire responses. It must be noted again that although the influence-in this case, identification - of a sustainable society characteristic would inevitably overlap with another (due to their systemic nature), for the purpose of identifying the most recurrent themes highlighted by the users, only the ones which directly refer to the users' responses 
were listed. A recurrent theme was considered as 'significant' when half or more of the users mentioned it.

\section{Results and findings}

Overall, approximately 50 students showed interest in taking part of the project, out of which 17 signed up (multicultural group between the ages of 18-27, all living in Butler Court Halls of Residence at Loughborough University). All of them participated under the 'Individual' category, and four teams were formed under the 'Team' category.

The participants' level of involvement in the project varied from participant to participant. Through the analysis of their individual interactions, their attendance at one-toone events, input and exchanges within the social network, etc., their level of activity was categorized into four different trends or levels (Table 5).

\subsection{Dynamics between the formal and informal learning activities and settings}

- Special Events As described in Table 2, the 'Special Events' consisted of one-to-one activities. This type of event, although not strictly academic, fits a model of formal learning setting (Martins et al. 2006; Vare and Scott 2007), where instructed (taught) learning was guided and delivered at the university by an expert in the particular area, and participants had to attend at a certain time and date. Altogether, 14 one-to-one events were carried out successfully.

When analysing the data gathered during these events, key issues stood out. With regard to the achievements of the events as such, the participants found the events interesting, informative and meaningful. Participants expressed their enjoyment at 'having to do/make things rather than just listen to someone' (SP-10). Nevertheless, turnout proved to be difficult during almost all the one-to-one events, the average number of attendance being 7-8 participants. This issue reflected on the categories of participation too; 'Individual participation' grew with every event while 'Team participation' did not. It became evident during the project that participants found it difficult to get all the members of a group to join the same events. Certain days of the week (i.e. Fridays, holidays) and academic commitments had an impact on attendance too.

$\mathrm{ZZ}, .$. You forgot the competition?! OMG. You really have to prove your loyalty to the Green Rabbit Team! :-/ (SP-10, Social Network Platform comment).

In regard to the appeal, the events had for different participants; the events in which sustainability issues were not clearly identified as 'the core theme' or which used an

Table 5 Participants level of activity

\begin{tabular}{lll}
\hline Rate of participation in the project activities & Level of activity & Number of participants \\
\hline 17 participants in total & \\
$80-100 \%$ & Very active & 9 \\
$60-80 \%$ & Fairly active & 2 \\
$40-60 \%$ & Not very active & 5 \\
$40 \%$ or less & Not at all active & 1 \\
\hline
\end{tabular}


intriguing 'fun' title, attracted more participants. For example, Quiz nights, International Buffet, Bring and Buy Sale. Participation was a recurrent topic all through the project, and for this reason, it is discussed in detail under the Sect. 6.4.

- Social Network Platform This platform collated the interactions of the 'Daily Activities', the 'I Say, I Do, I Make' activities, the 'special events' feedback, and the blogs, forums, photographs, and videos postings. These types of activities fit a model of informal learning setting, where learning is self-directed, without the assistance of an educator, and are guided by the individual's interests (Martins et al. 2006; Barth et al. 2007; Vare and Scott 2007).

Overall, there were 12 'Daily Activities', and 12 'I Say, I Do, I Make' activities carried out successfully. The participants' engagement and interaction with the social network platform proved to be comparatively easier than that of the 'Special Events'. Again, 'Individual participation' was more successful than 'Team participation'. The fact that the platform could be accessed and used at the participants' own will-in their chosen time and day - made it very convenient. The platform provided a space to propose and develop new activities. Also, the opportunity to discuss issues, skills and opinions that were important for them and could affect both their personal and professional lives. The platform also gave a sense of intimacy and safety to its participants, encouraging them to reveal deeper insights into their lives, feeling and emotions. An outstanding example of this was the 'Gratitude Journal' challenge, which attracted the highest interaction of all 'virtual events'. This challenge was based on a recognised positive psychology technique for increasing Happiness that consists in keeping a journal in which things for which you are currently grateful are listed (Sheldon and Lyubomirsky 2004). It required the participants' to create the journal (Blog) and make daily entries of between 3 and 5 things.

Earth Hour Today ... I switched off my lights at 8.30 tonight. And I thought ... how bad can it be having a shower in the dark anyway?? ... I couldn't see a thing! ... I couldn't know how much shampoo I should squeeze out ... Then, I just have to keep on feeling for the walls for my towels and clothes. ... it really makes me be grateful for our 5 senses that we are so luckily born with ... (SP-06, Gratitude Journal Blog, Social Network Platform).

\subsection{Embedding happiness and sustainable lifestyles in HESD}

On the subject of the project's contribution to happiness and more sustainable lifestyles, the evidence confirms that these were significant themes that emerged during the project. The use of the happiness and sustainable lifestyles characteristics (Escobar-Tello and Bhamra 2009) illustrated in Fig. 1 were a key aid used in its analysis. Through this analysis, it was possible to identify that all the characteristics relating to happiness, a sustainable society and lifestyles were triggered. This 'triggering' condition indicates that participating students gained, through their micro-community, active real experience, knowledge and awareness of the systemic conditions of society (particularly sustainable societies), and consequently mindfulness of the impact that their behaviours, values and actions pose on it. On reflection, this addresses the emancipatory and systemic perspective needed for HESD frameworks to be successful (Wals and Jickling 2002; Vare and Scott 2007).

As noted in previous sections, these characteristics (happiness and sustainable lifestyles) are 'variables' that form an interlocking system. Therefore, triggering one characteristic 
will trigger another. Nevertheless, for the purpose of simplicity, the following paragraphs endeavour to examine each one separately, and when significant connections to other triggers have been identified, these have been highlighted by underlining. Their importance escalated as the project evolved:

- Building social interaction and sense of community-at the outset participants did not know each other; this made their attitudes and interactions very timid during the first week of the project. Nevertheless, as the project unfolded, it was observed that community, collaboration and friendships developed, and participants' social interaction became stronger; week by week, participants voiced their opinions with more confidence and their behaviours became more pro-active during the different events.

By the third week of the project, it was clear that a sense of community had developed among the participants. Particularly among the 'very active' participants, it became usual practice to share time, activities and skills with each other. Strong friendships developed too.

- Pro-active citizenship-participants began proposing their own 'social activities'being more pro-active - and meeting up for other reasons besides the SLEUTH project. The increasing interaction observed during the 'I Say, I do, I make' activities provided important evidence of this. Through the organisation of one-to-one events by their own initiative, participants began sharing products and services and appreciating the benefits of slow life or 'slow change'. Some events were 'just for fun' (i.e. 'games night' and 'cooking nights') and others had a clear focus on sustainability issues in mind (i.e. 'The Big Tech Turn-Off).

As the project unfolded, a pro-active attitude became the norm, particularly among the 'very active' participant's images, videos and comments were updated and exchanged on a daily basis.

- Virtuousness skills and ethics-as the project developed, participants realised the importance of 'sustainability', of their role in shaping SLEUTH, and the value in meeting its aims for the good of the university's community and the planet. By the end of the project, there was evidence of higher levels of critical thinking and awareness among the group. The 'Waste and Recycling' special event provided outstanding evidence of this. With the aim of shaping the environmental future of the university, the participating teams were asked to come up with a logo and environmental theme to use as a symbol to engage students in this sort of activities. Participants took the task seriously, designed their logos during the workshop and presented their arguments to back them up. A strong debate drove the remainder of the session; debate which included deep and complex issues - such as "what motivates people to become more sustainable' - which brought them to significant conclusions such as 'fining people and paying people to recycle is not the way forward, it needs to become habit'.

Furthermore, changes in knowledge and awareness towards sustainability were the strongest theme underlying the social network platform's interactions; these are triggers of virtuousness skills and ethics characteristics. The majority of blogs and forums discussed environmental and social impacts due to human activities, which dialogues aimed to raise awareness but also to suggest positive ways to counteract or minimise these impacts. These also provided specific evidence with regard to low material consumption, sharing products and services, and slow change considerations and strategies.

Finally, contribution to sustainable lifestyles' characteristics such as Holistic Health and Education were successfully met through these discussions too. In contrast, specifically 
tailored activities to trigger these-i.e. 'volunteering' and 'skills exchange'-were not very popular. This type of activities required a certain amount of time and dedication; academic commitments and poor interest were found to be key barriers for engagement.

\subsection{Energy savings}

The energy savings data provided exceptional evidence on how 'low material consumption' was triggered effectively. When comparing the energy consumption in the chosen Halls of Residence during the period that SLEUTH project ran versus the same period in 2009 , it is clear that there were significant energy savings that amount to $7.77 \%$. Figure 2 illustrates this in detail. Week -1 and week 0 correspond to the 2 weeks prior to SLEUTH project's launch. Week 1-week 8 corresponds to the 8-week period in which SLEUTH project took place. Finally, week 9 corresponds to the week after SLEUTH project's closure (first week of the university's holiday period).

It is difficult to say whether the energy reductions were only because of SLEUTH, but the data suggest that the project did make a difference. Furthermore, the energy comparison of this same period between other university halls that are similar in terms of facilities showed that the chosen Halls of Residence was the only hall that consistently decreased its energy consumption. Other halls presented an 'up and down' pattern. The energy consumption per bed was significantly lower than the other halls. No other halls experienced the same energy reductions. Even, when looking at the halls occupancy comparison between 2009 and 2010, the average is the same; therefore, the energy savings cannot be attributed to having lower occupancy during the SLEUTH project.

\subsection{Overall participation}

The issue of 'participation' was one of the most complex topics of the project results. As discussed in previous sections, although the project was successful in triggering happiness and sustainable lifestyles effectively, the number of participants was a comparatively small

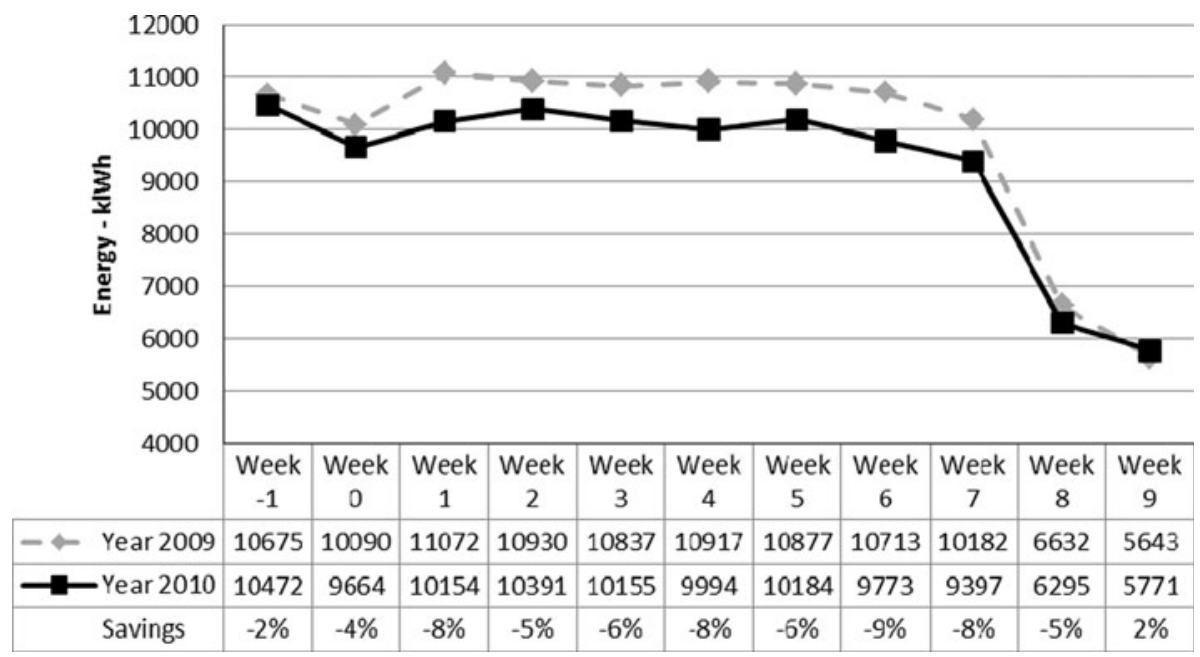

Fig. 2 Chosen halls of residence energy consumption 2009 versus 2010 
number of students living at the chosen Halls of Residence. The main finding in this respect then is the confirmation that engagement in sustainable issues and lifestyles is not easy; it requires real change collaboration and commitment.

The project offered a wide and interesting portfolio of rewards with the aim of motivating students' participation. However, participants had to play an active role in order to win these and evidence suggested that not all the students were willing to do this. Although the project aimed to engage widely, according to the participants' feedback, the young students' priorities-particularly in their first year-are focused towards social recognition, glamour and entertainment. Unfortunately, the project activities did not always fall under the usual student's ideas of entertainment (i.e. parties and drinking). Many of the events implied involvement in activities which were not always perceived as 'cool' among peers. As a result, the project attracted (in general) a certain type of student who had already some interest in sustainable issues and/or is interested in international cross-cultural exchanges.

It was observed in general terms that the participants' level of engagement was superior when points, or raffles, were offered as incentives. For example, activities which did not offer this sort of incentives - such as voting and rating events, or contributing to events' feedback discussions - were not successful. Participants admitted that the rewards played a main role in making SLEUTH attractive; not all participants felt genuine interest in the core aims of the project, but rather in the competition and rewards as such. Having said this, the participants acknowledged that this perspective-their attitude-changed and evolved as they learned and grew throughout the project.

\subsection{Happiness and sustainable lifestyles questionnaire}

The following subsections report on the collated results and findings of the 'Happiness and Sustainable Lifestyles' Questionnaire. These results complement the qualitative results and analysis of the findings discussed in previous sections.

All in all, eleven questionnaires out of 17 were received back; all from very active participants. However, only ten were complete and used as data. Although the response rate was high among the sample, not all were returned. One of the reasons that could explain this is that the participating students were at the end of their academic term-either preparing for exams or already leaving for their holidays.

\subsubsection{Measuring happiness}

Stage one of the Questionnaire focused on measuring the users' happiness before and after SLEUTH. The results indicated that SLEUTH contributed positively to the participant's happiness. When referring to their present happiness (see Fig. 3), ten out of ten participants reported being 'happy' or 'very happy' by the end of SLEUTH. Four reported an increase in their evaluation of happiness, and six maintained the same measures.

With regard to the participants' appreciation of life's overall happiness (see Fig. 4) this refers to 'looking back to your life'-SLEUTH had a positive impact too. Ten out of ten reported being 'fairly happy' or 'very happy' by the end of SLEUTH. Two reported and increase, seven maintained the same measures and one reported one point less.

\subsubsection{Measuring enjoyment of participating in SLEUTH project}

The results of the second stage of the questionnaire indicated that all participants enjoyed taking part in the project. The participants manifested with strong concurrence that the 
Fig. 3 Measuring happinesspresent

Fig. 4 Measuring happinessoverall
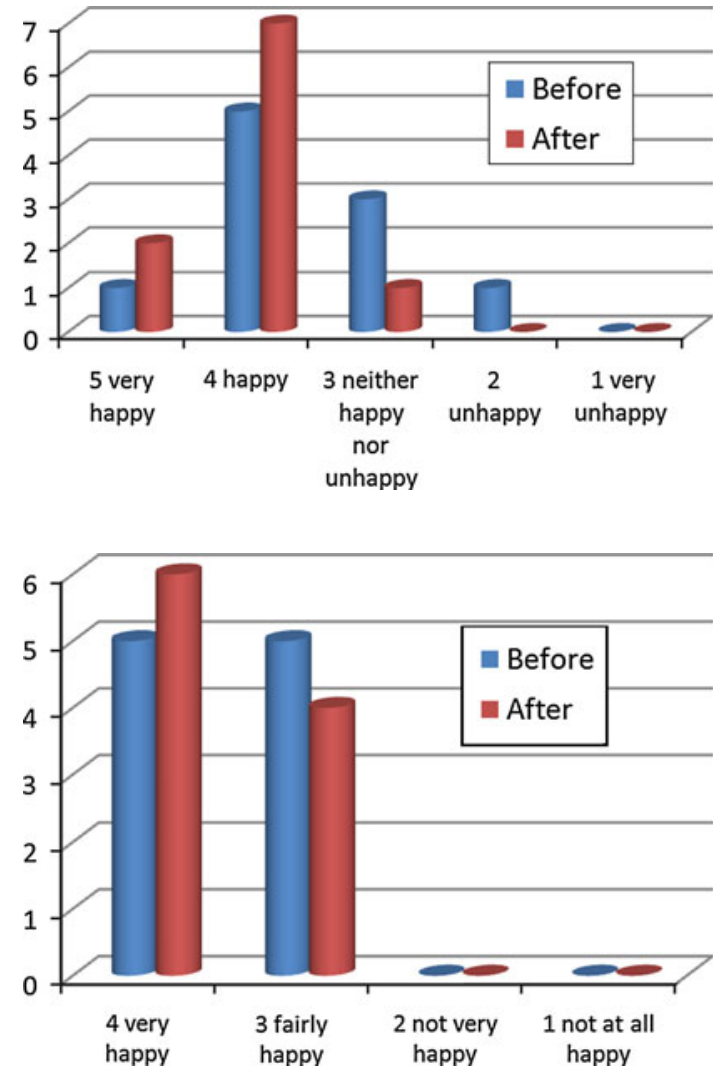

main topics that contributed in making their experience enjoyable were the events themselves-being interesting and fun-having an opportunity to socialise and share with others, the recognition that they had raised their environmental awareness, and the appreciation that they had learned from other cultures and global issues.

Based on how these topics overlapped with the sustainable society characteristics, it was identified that 'High Social Interaction', 'Virtuousness Skills and Ethics', 'Low Material Consumption' and 'Holistic Health and Education' were the most recurrent themes valued by SLEUTH participants' opinions.

\subsubsection{Measuring SLEUTH project's influence on participants' lifestyle}

I'm more prone to save energy and to care about the world in general. I appreciate the things that I have now and I will make an effort to help people that don't know about it too much. (SP-11, Happiness and Sustainable Lifestyles Questionnaire)

When asked about how SLEUTH project affected the participants' lifestyle in general, the majority agreed that this experience did cause a significant impact. Their detailed responses pointed out to 'Environmental awareness' - specifically 'energy' related issues, 'Global awareness' and 'Taking notice' as the most significant topics that influenced their lifestyles (see Fig. 5). 
Fig. 5 SLEUTH's influence in participants' lifestyle_topics

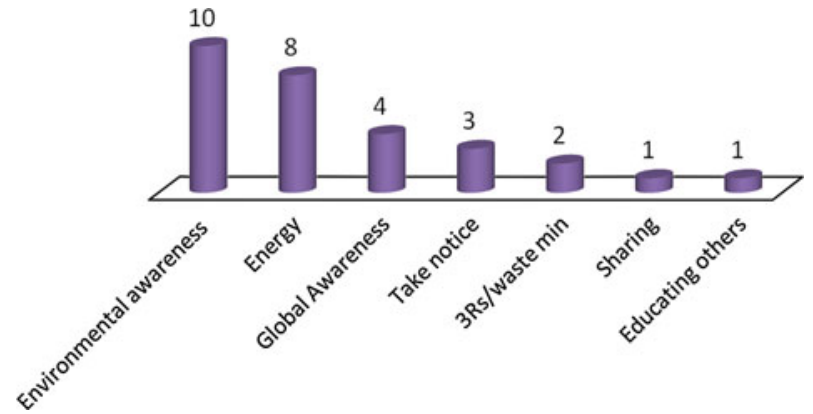

The analysis of how these topics overlapped with the theme-ing coding system enabled the identification of 'Virtuousness Skills and Ethics', 'Low Material Consumption', 'Holistic Health and Education' and 'Pro-active citizenship' as the most recurrent themes (see Fig. 6). Time constraints limited further research, but for future research, it would be interesting to evaluate whether these influences lasted some time after the end of the project.

\subsubsection{Measuring SLEUTH project's benefits and barriers}

With the aim of capturing the participants' attitudes towards the project as such, the participants were asked for their perception regarding SLEUTH benefits and barriers. Above all, these results allowed capturing important allusions to sustainable attitudes and behaviours.

Participants responses, illustrated in Fig. 7 below, showed strong consensus in that 'making new friends', and being 'fun' were the highest benefits of participating in SLEUTH. These were followed very closely by 'learning about sustainability', 'being part of a community', 'helping the environment', 'sharing and interacting with others' and the 'rewards'. These results - in cross-relation to the results illustrated in Fig. 6-offered an interesting contrast in opinion. This contrast suggested that although the users appreciated and found value in these benefits (community and social interaction), the activities or stimulus during the project were not strong enough to cause considerable lifestyles changes in these areas. This finding coincides also with the data obtained from the one-to-one

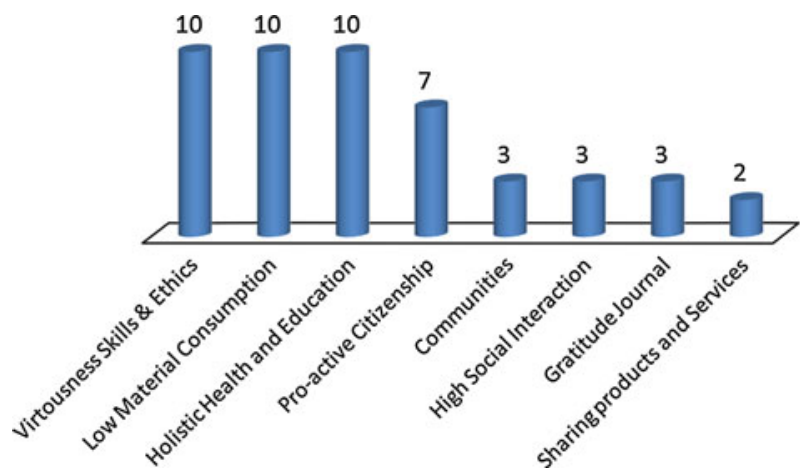

Fig. 6 SLEUTH's experience influence in participants' lifestyle — themes 


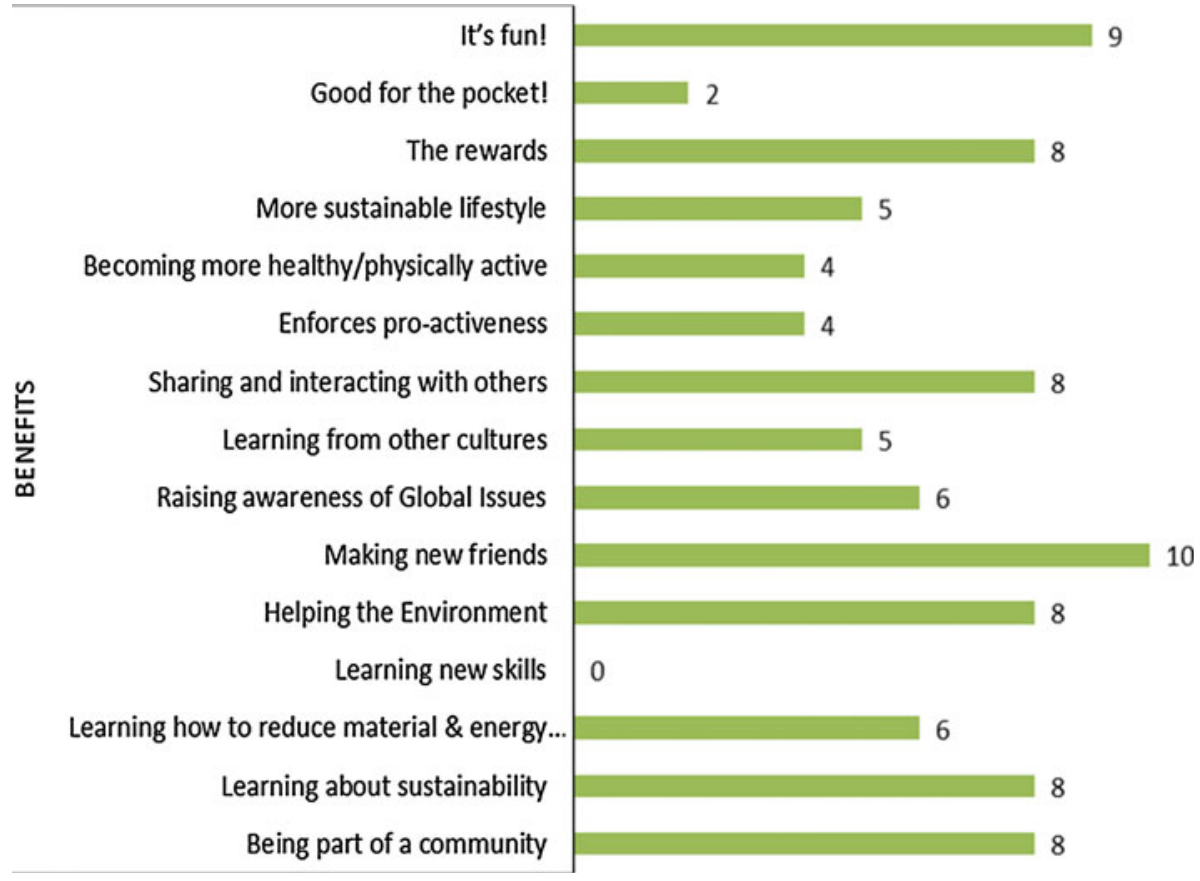

Fig. 7 SLEUTH's benefits

events and the social network platform, specifically with 'team interaction' which proved to be poor in comparison with 'individual interaction'.

It makes you feel proud that you can be part of the green warrior. (SP-08, Happiness and Sustainable Lifestyles Questionnaire)

When looking at the barriers perceived by the SLEUTH participants, it was observed that 'time commitment' came up in rank 1 without any contest. This was followed by 'lectures and assignments'. The participants stated that the frequency of the events was high and therefore made it difficult to participate in all of them. Some added that the events were 'too much hassle' (i.e. long). Other comments suggested that the low participation numbers themselves and the lack of high profile motivators (i.e. a role model/celebrity) were barriers too. These results clearly reflect on the users' academic responsibilities and age group-related interests (i.e. social pressures).

\section{Conclusions}

Based on the results and findings presented in this paper, it can be concluded that SLEUTH was a thriving project which achieved its aims successfully. It was a good example of an alternative route in the path for bringing university students towards more sustainable lifestyles where by complementing other HESD initiatives it could offer more 'rounded' strategies. The evidence also contributes towards the identification of 'effective' strategies for meeting the university's aim of becoming a 'demonstrator campus'. It provided an 
alternative example of how different areas of a university can work together to embed sustainability at their core.

In more detail, the project effectively contributed to 'greening' the campus; it addressed energy use by reducing the participants' energy consumption within their halls of residence and in their daily activities in approximately $8 \%$. This result offers great potential energy savings in future replications of this type of project. If these results were possible with a relatively small group of participants, the results could be more significant if more people are recruited (i.e. extend the competition to other halls of accommodation, the whole university).

Regarding the benefits and values of this form of project, it can be concluded that this type of initiative can effectively trigger sustainable lifestyle characteristics, including a sense of community, of belonging and cohesion, as well as the participants' self-esteem, satisfaction with themselves and their actions. In this way confirming its potential to foster active real experience, knowledge and awareness of the systemic conditions of societies, as well as its potential to harness the social capital (increasing its participants happiness/wellbeing, mindfulness and accountability).In fact, specifically with regard to happiness, it was possible to validate that the project triggered and resulted in an improvement in happiness; particularly, the 'present happiness' time frame, which is the one strictly related to the influences of current daily activities on individuals being assessed. All in all, the initiative allows its users to have fun, meet and make new friends, while appreciating other cultures, and furthering their learning about urgent issues (self-directed learning through a social learning process). In a significant way, the participants develop a strong sense of gratitude for the things they have; interact in an active way with each other; become more confident as the project develops; and feel positive about the opportunity to contribute towards a better planet/world.

Thank you for this Sleuth project. It spices up my stay over here. I will surely miss this when I go back to Malaysia in June.

(SP-07, Happiness and Sustainable Lifestyles Questionnaire)

In terms of the weaknesses, 'participation' and 'time commitment' proved to be the major barriers. These are important barriers that, for future reference, should definitely be addressed in order to improve the participants' potential to acquire sustainable lifestyles. The main being in this respect, the need to find successful motivators that increase participants' involvement in activities that enhance community ties, particularly team activities.

Now, from an HESD perspective, the findings provided evidence of the initiative's potential to be a successful path to respond to 'education for sustainability'. The one-to-one platform and the social network platform results showed how, through their particular dynamics, they complement each other by reaching the participants in different ways that attracted and suited them as per their needs (i.e. extraversion vs. privacy). In addition, this 'balance' corroborated previous findings on the enhanced possibilities in developing key competencies for sustainable development when combining both formal and informal learning activities and settings (Barth et al. 2007; Vare and Scott 2007; Cortese 2003). This initiative is indeed an important reflection on the challenges and opportunities of these learning settings when in pursuit of HESD. Although the specific sample of this project was too small to be of statistical significance, it is valuable representative data of what this type of combined education initiatives can achieve, even in short periods of time (Martins et al. 2006). This type of initiative is an effective example of a 'programme framework' for HESD that in a balanced way moves away from indoctrination and instead leans towards 
pro-activeness, self-organisation and voluntary collective action; where through a social learning process the participants have the opportunity to discuss, question and learn about sustainability in a non-prescriptive way; where they can begin finding answers to the question 'what difference can I make?' (Foster 2001, p. 162).

Ultimately, the empirical experiences of this project have pointed out that the novel approach used in this initiative-embedding happiness triggers and sustainable design characteristics within products/services/systems - offers an effective strategy to promote a systemic understanding and awareness of sustainability, reflection and critical thinking; as discussed earlier in detail (Sect. 6.2), its approach affects 'active users' in their 'Virtuousness Skills and Ethics', 'Low Material Consumption' and 'Holistic Health and Education'; and in its majority, their 'Pro-active citizenship' and 'High social interaction'. In this way, providing an important contribution towards the equipping of the student population with the necessary skills and capabilities to shape and lead sustainable lifestyles. Furthermore, the evidence suggests a strong potential in influencing participants' willingness to adopt the initiative's learning in their lifestyles, in both the long and short term. In particular, with regard to exercising their acquired environmental and global awareness, reducing their energy and $\mathrm{CO}_{2}$ footprint, and implementing 'low material' lifestyles.

The latter are clear examples of how the type of dialogues that emerge in this initiative's approach revolve around the building blocks of a sustainable society where its citizens are likely to be happy. Addressing the 'sustainable society characteristics' is effectively a proposal for unpicking the concept of sustainability, which as suggested by Wals and Jickling (2002), Vare and Scott (2007), Cortese (2003) among others, is positive in removing the limitations of using the term 'sustainability' and therefore a successful approach to give a clear idea of the overarching goals to be achieved. By doing this, this initiative successfully enables the students' potential and equips them with the competencies to think in a critical way, value different ways of thinking, strive in complex undirected scenarios and capable of co-creating solutions which simply makes them more rounded citizens.

As already mentioned throughout this paper, all of the above issues have been highlighted and identified as key influencers of the sustainable society characteristics, in other words, key building blocks of 'Sustainable' and 'Happy' societies (Escobar-Tello 2011). From this perspective and based on the results and findings discussed in this paper, the additional benefit of the focus of happiness and sustainable society characteristics compared to other HESD approaches is made clear: it shapes the HESD approach in an effective and successful holistic way that proposes new ways of thinking about ESD learning. Ultimately, by including deep and genuine values such as happiness in HESD frameworks, there is the potential for greater reach and impact, resulting in a more systemic understanding of sustainability, sustainable social practices and its value to students.

\section{References}

Abdallah, S., et al. (2009). The (un)Happy Planet Index 2.0-Why good lives don't have to cost the earth Report. London: NEF. http://www.happyplanetindex.org/learn/download-report.html. Accessed July 27, 2009.

Barth, M., et al. (2007). Developing key competencies for sustainable development in higher education. International Journal of Sustainability in Higher Education, 8(4), 416-430.

Brülde, B. (2007). Happiness theories of the good life. Journal of Happiness Studies, 8(1), 15-49.

Cooper, T. (2000). Product development implications of sustainable consumption. Design Journal, 3(2), $46-55$. 
Cortese, A. (2003). The critical role of higher education in creating a sustainable future. Planning for Higher Education, 31(3), 15-22.

Csikszentmihalyi, M. (2002). Flow-The classic work on how to achieve happiness (2nd ed.). London: The Random House Ltd.

Daily, G. C. (1997). Nature's services: Societal dependence on natural ecosystems. Washington, DC: Island Press.

Diener, E. \& Scollon, C. (2003). Subjective well-being is desirable, but not the Summum Bonum. In: University of Minnesota at Interdisciplinary workshop on Well-being. October 23-25, 2003, Minneapolis, USA. http://www.tc.umn.edu/ tiberius/workshop_papers/Diener.pdf. Accessed June 9, 2007.

Diener, D., et al. (2003). The evolving concept of subjective well-being: The multifaceted nature of happiness. Advances in Cell Aging and Gerontology, 15, 187-219.

Escobar-Tello, M. C. (2011). Explorations on the relationship between happiness and sustainable design. Thesis, (PhD). Loughborough University.

Escobar-Tello M. C. \& Bhamra T. A. (2009). Happiness and its role in sustainable design. In Proceedings of Design Connexity 2009: 8th International Conference of the European Academy of Design (pp. 149-154). April 1-3, Aberdeen, Scotland, UK.

Fadeva, Z., \& Mochizuki, Y. (2010). Higher education for today and tomorrow: University appraisal for diversity, innovation and change towards sustainable development. Sustainability Science, 5(2), 249-256.

Ferrer-Balas, D., et al. (2010). Going beyond the rhetoric: System-wide changes in universities for sustainable societies. Journal of Cleaner Production, 18, 607-610.

Foster, J. (2001). Education as sustainability. Environmental Education Research, 7(2), 153-165.

Hawken, P., et al. (1999). Natural capitalism. http://www.natcap.org. Accessed Nov 4, 2007.

Hinte, E. (1997). Eternally yours - visions on product endurance. Rotterdam: 010 Publishers.

Jackson, T. (2008). Chapter 4: The challenge of sustainable lifestyles. In Flavin, C. et al. (Ed.), State of the world 2008-Innovations for a sustainable economy (pp. 45-60). London: Norton \& Company Ltd. http://www.worldwatch.org/files/pdf/SOW08_chapter_4.pdf. Accessed Feb 21, 2008.

Jackson, T., \& McBride, N. (2005). Measuring progress?-A review of 'adjusted' measures of economic welfare in Europe, prepared for the European Environment Agency. Guildford: Centre for Environmental Strategy.

Layard, R. (2005). Happiness-lessons from a new science. London: Penguin Books Ltd.

Lemonick, M. D. (2005). The biology of joy. Time Magazine, 7, 52-55.

Manzini, E. (2006). Design, ethics and sustainability-guidelines for a transition phase. Milano: DISIndaco, Politecnico di Milano. http://www.sustainable-everyday.net/manzini/. Accessed Oct 9, 2007.

Martins, A., et al. (2006). Education for sustainability: Challenges and trends. Clean Technologies and Environmental Policy, 8(1), 31-37.

Meadows, D. (2002). Dancing with Systems. The Systems Thinker, 13(2), (March 2002).

Meadows, D. et al. (2004). The limits to growth: The 30-year update. London: Earthscan.

Michaelson, J., et al. (2009). National accounts of well-being: Bringing real wealth onto the balance sheet report. London: NEF. http://www.neweconomics.org/gen/z_sys_publicationdetail.aspx?pid=279. Accessed Feb 11, 2009.

Miles, M. B., \& Huberman, A. M. (1994). Qualitative data analysis: An expanded sourcebook (2nd ed.). California: SAGE Publications.

Morse, J. M., \& Richards, L. (2002). Readme first_for a user's guide to qualitative methods. London: Sage Publications.

Narada, M. T. (1991). The Buddha and his teachings. Ven Narada Maha Thera commemoration. Singapore: Buddhist Publication Society.

Nath, B. (2003). Education for sustainable development: The Johannesburg summit and beyond. Environment, Development and Sustainability, 5(1), 231-234.

Papanek, V. (1985). Design for the real world. London: Thames and Hudson Ltd.

Robson, C. (2002). Real world research: A resource for social scientists and practitioner-researchers (2nd ed.). Oxford: Blackwell Publishers Ltd.

Sheldon, K. M., \& Lyubomirsky, S. (2004). Achieving sustainable new happiness: Prospects, practices, and prescriptions. In A. Linley \& S. Joseph (Eds.), Positive psychology in practice (pp. 127-145). Hoboken, NJ: Wiley.

Shove, M., et al. (2007). The design of everyday life (cultures of consumption). Oxford: Berg Publishers.

Sterling, S., \& Scott, W. (2008). Higher education and ESD in England: A critical commentary on recent initiatives. Environmental Education Research, 14(4), 386-398.

Sustainable Consumption Roundtable. (2006). 'I will if you will'-towards sustainable consumption. Report for the department for environment, food and rural affairs. London: Defra, ISBN: 1899581790. 
Toffler, A. (1970). Future shock. London: Pan Books Ltd.

UNESCO (2009). DESD 2005-2014: Review of contexts and structures for education for sustainable development 2009. Paris: UNESCO. http://unesdoc.unesco.org/images/0018/001849/184944e.pdf. Accessed Feb 9, 2011.

Vare, P., \& Scott, W. (2007). Learning for a change: Exploring the relationship between education and sustainable development. Journal of Education for Sustainable Development, 1(2), 191-198.

Veenhoven, R. (2001). World database of happiness, item bank-measures of happiness, introductory text. Rotterdam: Erasmus University Rotterdam. http://worlddatabaseofhappiness.eur.nl/hap_quer/tembankiintrotext.pdf. Accessed Aug 19, 2007.

Veenhoven, R. (2004). Sustainable consumption and happiness. In: The International workshop 'Driving Forces and Barriers to Sustainable Consumption'. University of Leeds, March 5-6, 2004, Leeds, UK. http://www2.eur.nl/fsw/research/veenhoven. Accessed Aug 19, 2007.

Wallis, C. (2005). The new science of happiness. Time Magazine, 7, 45-50.

Wals, A. E. J., \& Jickling, B. (2002). "Sustainability" in higher education-from doublethink and newspeak to critical thinking and meaningful learning. International Journal of Sustainability in Higher Education, 3(3), 221-232.

Weizacker, K., et al. (1998). Factor four. London: Earthscan Publication Ltd.

Whiteley, N. (1993). Design for society. London: Reaktion Books. 